\title{
A TEORIA DISCURSIVA DA APLICAÇÃO DO DIREITO: O MODELO DE HABERMAS*
}

\author{
Delmar José Volpato Dutra**
}

\begin{abstract}
RESUMO - O texto apresenta a teoria discursiva da aplicação do direito, tal como concebida por Habermas. Essa teoria constituiu um cruzamento entre normas procedimentais coativas e argumentação, de maneira que o procedimento juridicizado não deve pré-julgar ou dirigir a lógica da argumentação. No entanto, tal argumentação não pode ser entendida do mesmo modo que a argumentação moral, justamente devido às honras que deve prestar à legitimidade do direito oriunda do processo democrático, cuja racionalidade, nos argumentos morais, é mais complexa do que a da argumentação moral. Para clarificar esse ponto fundamental, é apresentada a recusa habermasiana da tese do caso especial, de Alexy.

PALAVRAS-CHAVE - Habermas. Filosofia do direito. Aplicação do direito. Discurso jurídico.
\end{abstract}

\begin{abstract}
The texts presents Habermas's theory of legal discourse. In this theory legal coercive procedures are intertwined with processes of argumentation, in such a way that those procedures should not determine the logic of argumentation. But such an argumentation cannot be understood in the same way as moral argumentation, since the rationality which makes a law legitimate is more complex than the one of moral argumentation. In order to clarify that fundamental point, Habermas's refusal of Alexy's special case thesis shall be exposed.
\end{abstract}

KEY WORDS - Habermas. Philosophy of law. Adjudication. Legal discourse.

\section{Da apropriação da teoria da integridade de Dworkin}

O paradigma discursivo da aplicação do direito é o Netuno de Habermas. Assim como na teoria da integridade de Dworkin, os conflitos entre justiça e eqüidade sugerem um terceiro ideal político, justamente a integridade, do mesmo modo como Netuno fora postulado antes de ser descoberto, para explicar o comportamento dos planetas mais próximos, ${ }^{1}$ assim também os conflitos entre o paradigma liberal e o social na teoria de Habermas, sugerem um terceiro paradigma, o processual: "Interpretando a política e o direito à luz da teoria do discurso, eu pretendo reforçar os

* O presente trabalho foi realizado com o apoio do CNPq, através de uma bolsa de pós-doutorado na Columbia University, para o projeto A racionalidade da jurisdição na teoria do direito de Dworkin e sua recepção crítica na filosofia do direito de Habermas, no período de 09/2003-08/2004.

** Professor da UFSC e Pesquisador do CNPq

Cf. DWORKIN, Ronald. Law's Empire, p. 184

\begin{tabular}{|l|l|l|l|l|l|}
\hline VERITAS & Porto Alegre & v. 51 & n. 1 & Março 2006 & p. 18-41 \\
\hline
\end{tabular}


contornos de um terceiro paradigma do direito, capaz de absorver os outros dois". ${ }^{2}$ Melhor dito, o paradigma procedimental evita os problemas do modelo liberal e do social. ${ }^{3}$ Nos termos da teoria de Dworkin, os "paradigmas aliviam Hércules da supercomplexa tarefa de colocar 'a olho' uma quantidade desordenada de princípios aplicáveis somente prima facie em relação com as características relevantes de uma situação apreendida do modo mais completo possível". Ou seja, o paradigma jurídico corporifica, sob o ponto de vista do conteúdo, "um pano de fundo de compreensão que os especialistas em direito compartilham com todos os demais membros do direito". ${ }^{4}$ O paradigma envolve os julgamentos do operador do direito desde sempre, de tal forma que a escolha do paradigma não é arbitrária, ou seja, escolhida. No entanto, "a pré-compreensão paradigmática não é incorrigível, uma vez que é testada e modificada no decorrer do próprio processo de interpretação". 5

Para Habermas, a racionalidade da jurisdição deve cumprir simultaneamente o predicado da segurança e da legitimidade. Nesse sentido, ele encontra, na teoria da interpretação construtiva de Dworkin, um fio condutor para realizar essa tarefa. Assim entendido, o modelo de Dworkin assegura "a integridade e condições de reconhecimento que garantem a cada parceiro do direito igual respeito e consideração" ${ }^{6}$ Portanto,

o princípio da "integridade" caracteriza o ideal político de uma comunidade, na qual os parceiros associados do direito se reconhecem reciprocamente como livres e iguais. É um princípio que obriga tanto os cidadãos, quanto os órgãos da legislação e da jurisdição a realizar a norma básica da igual consideração e do igual respeito por cada um. ${ }^{7}$

No entanto, "quando Dworkin fala de argumentos de princípios, que são tomados para a justificação externa de decisões judiciais, ele tem em mente, na maioria das vezes, princípios do direito que resultam da aplicação do princípio do discurso no código jurídico". 8 Essa formulação se constitui na chave da apropriação discursiva da teoria de Dworkin. ${ }^{9}$ Ou seja, tal teoria tem que ser defendida numa perspectiva processual que traduza as suas exigências idealizadoras nos termos dos pressupostos pragmáticos da teoria discursiva: "a ética do discurso recupera, de certa forma, a norma fundamental de Dworkin, ou seja, a do igual respeito e consideração". ${ }^{10}$

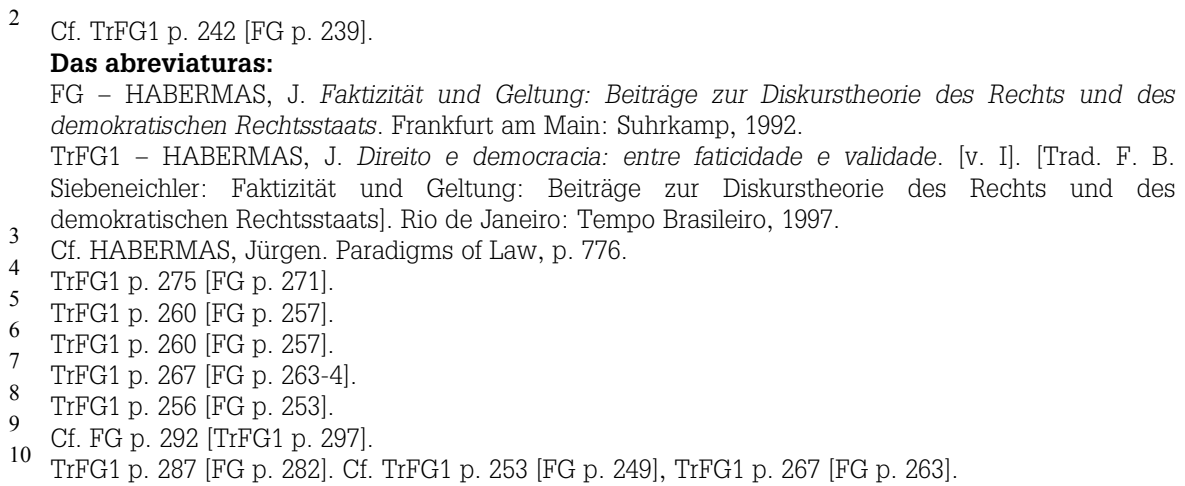


Uma das objeções à teoria de Dworkin é que, por se basear em princípios e por estes serem indeterminados, ${ }^{11}$ nos casos difíceis, diferentes conjuntos de princípios se aplicariam igualmente. ${ }^{12}$ Para enfrentar esse problema, Dworkin distingue competição entre princípios de contradição entre princípios. ${ }^{13}$ Em caso de conflito, a coerência do sistema leva a um esquema não-arbitrário de prioridade, ou balanceamento, ou acomodação entre ambos os conjuntos de princípios que concorrem. ${ }^{14}$ Por exemplo, o Código Civil Brasileiro, no art. 1.228, estabelece os direitos da propriedade: usar, gozar, dispor e reavê-la. Esse dispositivo conflita com uma regra de justiça segundo a qual as pessoas deveriam começar a vida em iguais termos, como defendido por Platão na República, ou na Declaração de que todos nascem iguais. Esse princípio, se for admitido, inviabilizaria o direito de herança, estabelecido na Constituição. Uma solução, para tornar tais normas coerentes, é estabelecer o imposto causa mortis. ${ }^{15}$

Günther torna mais preciso o problema da colisão de princípios - que, para Dworkin, não são contradições - pela distinção entre aplicação e fundamentação, ${ }^{16}$ de tal forma que "a validade da norma não garante por si só a justiça no caso singular". ${ }^{17}$ Portanto, para se garantir a justiça, no caso concreto, é necessário que todo o conjunto de normas seja avaliado, a fim de se saber como ele vai configurar-se para resolver o caso específico. Para tal, é necessário estabelecer quais descrições são significativas e, em razão disso, qual das normas é adequada à situação. ${ }^{18}$ Isso significa que a norma tem um componente descritivo que é sua condição de aplicação. No final, o conjunto de princípios se torna flexível, encontrando uma determinada configuração em cada situação de aplicação.

Contra essa proposta elegante de Günther Habermas objeta que ela evita a indeterminação assumindo-a, tendo como conseqüência uma atenuação preocupante da segurança jurídica. Ou seja, a teoria de Günther resolve a tensão entre faticidade e validade da decisão judicial de maneira muito desfavorável à faticidade própria do direito. Adiante tratar-se-á com mais vagar a teoria de Günther. Nesse mesmo diapasão já se objetou contra Dworkin que a reconstrução, caso a caso, do direito leva a uma aplicação retroativa. ${ }^{19}$ A crítica a Günther se dá em

11 Cf. TrFG1 p. 270 [FG p. 266].

12 Cf. DWORKIN, Ronald. Law's Empire, p. 266

13 Cf. DWORKIN, Ronald. Law's Empire, p. $272 \mathrm{~s}$

14 Cf. DWORKIN, Ronald. Law's Empire, p. 268-269.

15 O exemplo é sugerido por Dworkin [Cf. DWORKIN, Ronald. Law's Empire, p. 178-9, nota 7].

16 Cf. TrFG1 p. 269 [FG p. 265].

17 TrFG1 p. 270 [FG p. 266].

18 Cf. TrFG1 p. 271 [FG p. 267-268].

19 Cf. TrFG1 p. 272 [FG p. 268-269]. Kress imputa à teoria de Dworkin tal problema: KRESS, K. J. Legal Reasoning and Coherence Theories: Dworkin's Rights Thesis, Retroactivity, and the Linear Order of Decisions, p. 369-402. Tal acusação é grave, pois um dos pontos centrais da teoria de Dworkin é o combate à discricionariedade do juiz, defendida pelo positivismo para a aplicação do direito, nos casos difíceis, sob o argumento de que isso significa uma aplicação retroativa do direito, atentando contra o uso legítimo da coerção, por parte do Estado, que deve presumir o prévio conhecimento da lei, além de implicar uma forma de legislação não-democrática. Tal discricionariedade seria evitada para Dworkin pela introdução de princípios no direito, os quais já estariam po- 
razão de a coerência operar no nível da aplicação, visto que, com isso, "o sistema degenera num catálogo de topoi e perde o poder de garantir a certeza legal". ${ }^{20}$ A teoria da coerência sozinha não resolve o problema da aplicação, pois assim como normas não regulam sua própria aplicação, um sistema não pode criar de si mesmo respostas corretas. Para isso, pessoas e procedimentos são necessários. Habermas abandona a teoria da coerência, visto ser ela um postulado elementar de racionalidade que precisa ser complementado. ${ }^{21}$ Ou seja, Günther separa demais aplicação e fundamentação, não resolvendo adequadamente a tensão entre a faticidade e a validade do direito. ${ }^{22}$

\section{Da teoria discursiva da aplicação do direito}

Apesar de correta, nos seus elementos básicos, como a prioridade do justo sobre o bem e a defesa de uma aplicação do direito que satisfaz aos predicados da legitimidade e da segurança, a teoria de Dworkin é criticável por sua operacionalização solipsista. De fato, Dworkin ancora as exigências normativas da teoria legal "no ideal da personalidade de um juiz, que se distingue pela virtude e pelo acesso privilegiado à verdade" 23 e não pela prática da argumentação. O procedimento tem que ser "mais importante do que propriedades individuais, como a capacidade para escolha racional, ou boas intenções, ou motivações apropriadas". ${ }^{4}$ Segundo Habermas, o autor de Law's Empire reconhece esse núcleo processual da integridade assegurada juridicamente, quando vê o igual direito às liberdades subjetivas como estando fundadas no direito às iguais liberdades comunicativas. ${ }^{25}$ Nesse sentido, ele faz coro a uma objeção que já fora levantada por Michelman:

o que está faltando na concepção de direito de Ronald Dworkin como integridade (jurídica) [...] é diálogo. Hércules, o juiz mítico de Dworkin, evita outras pessoas. Ele é também excessivamente heróico. Suas construções narrativas são monólogos. Ele não conversa com ninguém, exceto através de livros. Ele não tem encontros. Ele não se reúne com ninguém. Nada o estremece. Nenhum interlocutor viola o isolamento inevitável de sua experiência e perspectiva. Mas, depois de tudo, Hércules é só um homem. Ele não é toda a comunidade. Nenhum homem ou mulher pode ser toda a comunidade. ${ }^{26}$

sitivados, de tal forma que, quando usados para resolver um caso difícil, evitariam o problema da aplicação retroativa da lei. Ademais, no caso de dois ou mais conjuntos de princípios a disputarem a resposta correta para o caso, a dimensão da moralidade evitaria o arbítrio do juiz na escolha entre uma ou outra formulação dos princípios.

20 ALEXY, Robert. Jürgen Habermas's Theory of Legal Discourse, p. 1028.

21 Cf. ALEXY, Robert. Jürgen Habermas's Theory of Legal Discourse, p. 1028.

22 Cf. McCORMICK, John P. Habermas's Discourse Theory of Law: Bridging Anglo-American and Continental Legal Traditions?, p. 741.

23 TrFG1 p. 278 [FG p. 274].

25 HABERMAS, Jürgen. "Between Facts and Norms": an Author's Reflections, p. 941.

25 Cf. TrFG1 p. 277 [FG p. 274]. Cf. DWORKIN, Ronald. Taking Rights Seriously, p. 273.

26 MICHELMAN, Frank I. The Supreme Court 1985 Term. Foreword: Traces of Self-Government, p. 76. 
Por isso, a crítica ao solipsismo de Dworkin tem que "fundamentar os princípios do processo na figura de uma teoria da argumentação jurídica, que assume o fardo das exigências ideais até agora atribuídas a Hércules". ${ }^{27}$ É preciso traduzir as exigências ideais que Dworkin faz nos termos de um procedimento que faça jus tanto ao ideal da busca da única resposta correta, quanto à falibilidade desse empreendimento. ${ }^{28}$ Nessa formulação, “'correção' significa aceitabilidade racional, apoiada em argumentos". ${ }^{29}$ Argumentos são cadeias de razões que surgem num processo argumentativo, ou seja, "argumentos substanciais jamais são 'cogentes', no sentido de um raciocínio lógico (que não é suficiente, porque apenas explicita o conteúdo de premissas), ou de uma evidência imediata" [...] Por isso, "não há um fim "natural' no encadeamento dos possíveis argumentos substanciais". ${ }^{30}$ Trata-se de uma concepção pragmática de argumentação. A argumentação assim concebida motiva a uma aceitação racional de um ato de fala. Os argumentos têm a faculdade de motivar a aceitação, mas conservam um traço de faticidade, ou seja, do tempo em que surgiram. Mesmo Hércules está marcado por essa temporalidade, podendo suas reconstruções ser criticadas. Esse processo interminável de argumentação requer que se especifiquem suas condições e que seja concebido como possível o progresso cumulativo de um processo de aprendizagem. Tal processo assegura que razões e informações "possam desenvolver a força de motivação racional inerente a eles. A noção de argumento é pragmática: o que conta como boa razão se manifesta no papel desempenhado no jogo argumentativo de aceitação de pretensões de validade". ${ }^{31}$

A prática da argumentação pressupõe condições idealizadas que imunizam contra a repressão e a desigualdade, onde se busca o assentimento de um auditório universal. Para que uma pretensão possa ser aceita pelos afetados, ela exige a perspectiva da primeira pessoa do plural, a reversibilidade completa de todas as perspectivas dos falantes, ou seja, a perspectiva de todos os participantes.

Quem deseja participar seriamente de uma prática de argumentação tem que admitir pressupostos pragmáticos que o constrangem a assumir um papel ideal, ou seja, a interpretar e a avaliar todas as contribuições em todas as perspectivas, também na de cada um dos outros membros virtuais participantes. Com isso, a ética do discurso recupera, de certa forma, a norma fundamental de Dworkin, ou seja, a do igual respeito e consideração. ${ }^{32}$

No discurso de aplicação, especificamente, o interesse de todos os possíveis afetados fica em segundo plano, tendo já sido levado em consideração quando da fundamentação das normas; em primeiro plano aparecem os interesses das partes imediatamente afetadas. ${ }^{33}$

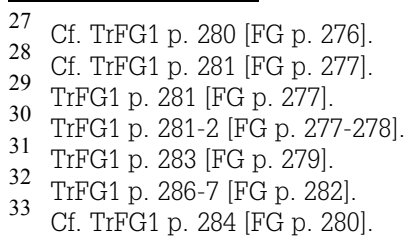


Aceitando-se a compreensão deontológica do direito e a teoria da argumentação, então, por um lado, o discurso tem que se manter aberto a argumentos de outras procedências, especialmente os pragmáticos, éticos e morais, já embutidos na validade da norma, oriundos do processo legislativo de legitimação e, por outro lado, à lógica da sua própria especificidade argumentativa: "a correção das decisões judiciais mede-se pelo preenchimento de condições comunicativas da argumentação, que tornam possível uma formação imparcial do juízo" ${ }^{34}$

\section{Da especificidade do discurso jurídico: contra a tese do caso especial}

O modelo discursivo do direito não pode ser equiparado ao modelo da ética discursiva. Nem o primado da moral pode levar à conclusão da tese do caso especial [Sonderfallthese] defendida por Alexy. ${ }^{35}$ Tal tese defende que o discurso jurídico seja um caso especial do discurso prático-moral em geral. É especial, devido a algumas peculiaridades do discurso jurídico, como a existência de norma positivada, a limitação de tempo para que uma decisão seja tomada, e o caráter coativo de suas decisões.

Habermas não concorda com a tese do caso especial e apresenta quatro objeções que tornam difícil a sua plausibilidade.

A primeira reside nas limitações da ação das partes no foro, as quais proíbem que tal ação seja medida pelo discurso racional. Na lide forense, "as partes não estão obrigadas à busca cooperativa da verdade, uma vez que também podem perseguir seu interesse". ${ }^{36}$ As partes podem agir estrategicamente. ${ }^{37}$ Contra essa objeção se pode argumentar que "os participantes do processo, por mais diferentes que sejam seus motivos, fornecem contribuições para um discurso, o qual serve, na perspectiva do juiz, para a formação imparcial do juízo", ${ }^{38}$ imparcialidade esta constitutiva para a fundamentação da decisão. Contra isso Neumann argumentou, mais tarde, que a posição de Habermas trata as partes do processo, não como participantes do discurso, mas como fontes de informação, pois se trata de um procedimento onde o juiz - o único participante - decide e fornece os argumentos, ao passo que todos os outros só providenciam informações. Um processo assim tem estrutura monológica e não dialógica, o que, segundo Neumann, contrariaria as idéias básicas da teoria discursiva do direito. ${ }^{39}$ Em defesa do modelo de Habermas e do seu próprio, Alexy argumenta que a posição de Neumann subestima a complexidade implicada na instituticionalização da racionalidade discursiva. Nela, se o juiz quiser operar com correção, terá que ouvir todos os aspectos

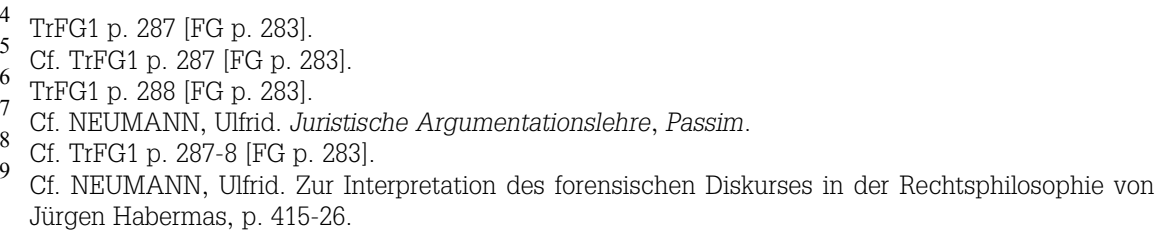


relevantes para decidir e argumentar auditatur et altera pars. E como as decisões estão submetidas a revisão, os argumentos têm que convencer a outros, o que é suficiente para uma interpretação discursiva do processo judicial. ${ }^{40}$ Portanto, quanto a essa objeção, o modelo parece defensável nos termos apresentados.

A segunda crítica remete à indeterminação do processo como insuficiente para se chegar a uma resposta correta. Para refutar essa tese, há que se mostrar o que Alexy não teria conseguido - que os princípios processuais e máximas de interpretação "apenas especificam as condições gerais [universais] do processo de discursos prático-morais em relação à ligação com o direito vigente" ${ }^{41}$ Alexy não teria conseguido estabelecer tal ligação, porque o discurso jurídico não é um caso do discurso moral, mas um caso do discurso neutro moralmente. Ou seja, Habermas nega a tese do caso especial, por razões que serão apresentadas abaixo.

A terceira crítica remete à demasiada aproximação feita por Alexy entre a correção moral e a jurídica e à sua defesa de uma harmonia muito estrita entre elas. Tal harmonia "não somente relativiza a correção de uma decisão jurídica, mas a coloca em questão enquanto tal" ${ }^{42}$ Isso ocorre, porque uma racionalidade completa da decisão judicial pressuporia a racionalidade da legislação. Como tal racionalidade não está disponível, devido às vicissitudes da política e ao amálgama de razões da legitimidade do direito, a própria correção da decisão judicial acabaria ameaçada, devido à impossibilidade ou dificuldade de realizar efetivamente tal aproximação. Para responder a essa objeção, é necessário reconstruir o direito vigente, como se pode encontrar exemplarmente em Dworkin, de tal forma que a decisão correta tenha que se encaixar num sistema jurídico coerente. O ponto em questão é que se trata de um sistema jurídico e não moral.

A quarta objeção se liga às modificações feitas por Günther na teoria de Alexy e Dworkin. Günther parte do pressuposto de que os sistemas morais são compostos por normas potencialmente colisivas entre si. Para ele, isso acontece, porque no significado de fundamentar imparcialmente uma norma não está contida a sua aplicação a um caso particular [ou a adequação de sua aplicação] ${ }^{43} \mathrm{Na}$ fundamentação, somente situações muito gerais são consideradas para possíveis aplicações. O discurso de fundamentação só consideraria as circunstâncias que permaneceriam iguais, em qualquer situação de aplicação. A contingência da história, que produz situações imprevisíveis, nos força a uma interpretação diferente do conjunto das normas válidas. O discurso de fundamentação não pode gerar um conjunto coerente de princípios para todos os possíveis casos de colisão. ${ }^{44}$ Por isso, ele propõe que se distinga fundamentar de aplicar uma norma, pois uma norma, que tivesse presente todas as possíveis situações para sua aplicação, seria uma norma

40 Cf. ALEXY, Robert. The Special Case Thesis, p. 377.

41 TrFG1 p. 288-9 [FG p. 284].

42 TrFG1 p. 289 [FG p. 284].

43 Cf. GÜNTHER, Klaus. Ein normativer Begriff der Kohärenz für eine Theorie der juristischen Argumentation, p. 168.

44 Cf. GÜNTHER, Klaus. Ein normativer Begriff der Kohärenz für eine Theorie der juristischen Argumentation, p. 182. 
perfeita. Ela poderia regular sua própria aplicação, porque, tendo presentes todas as suas possíveis aplicações, a adequação de sua aplicação pertenceria ao significado de sua validade. Isto é irreal - observa ele -, pois presume um tempo e saber infinitos. ${ }^{45}$ Ademais, se um princípio for definido pelo conjunto de suas aplicações, então cada aplicação a novas situações mudaria continuamente a significação dos próprios princípios, o que implicaria a impossibilidade de estabelecer a correção destes, independentemente de suas situações concretas de aplicação. ${ }^{46}$

Isso posto, para ele, a coerência não pode operar no nível dos princípios, pois nossos sistemas morais são compostos por princípios que, muitas vezes, colidem entre si. A coerência tem a ver, sim, com juízos particulares. Se for assim, a coerência só pode cumprir a tarefa de justificar princípios de maneira limitada, ou seja, só no que diga respeito à aplicação, de tal forma que a coerência não opera no tratamento da validade de um princípio independentemente das possíveis situações de aplicação. ${ }^{47}$ Portanto, imperioso é concluir: possíveis colisões de normas não são algo relevante para a validade destas. ${ }^{48}$

Nesse sentido, o discurso de aplicação complementa o de fundamentação ao acrescer a completude das circunstâncias, no caso concreto. Nesse discurso, as normas válidas prima facie funcionam como razão para decidir, fazendo com que uma delas se mostre adequada ao caso, a partir da descrição completa das circunstâncias. A descrição completa teria uma força heliotrópica de atrair a norma adequada para o caso. Isso não é uma operação mágica, como se verá, pois é operacionalizada pelo princípio do discurso. Sumariando, o discurso de aplicação faz com que obliquamente se alcance o ideal da norma perfeita, permitindo a renúncia daquela idealização de saber e tempo ilimitados no âmbito da fundamentação. ${ }^{49} \mathrm{Ou}$ seja, a coerência do sistema é recuperada no domínio de sua aplicação, de tal forma que a razão prática não se contradiz.

Hígida a distinção entre fundamentar e aplicar, Günther imputa a Alexy o tratamento do discurso jurídico como um caso especial do discurso de fundamentação moral. Alexy reconstruiu a argumentação jurídica sob o modelo da argumentação de fundamentação ${ }^{50}$. Para Günther, na verdade, o discurso jurídico é um caso especial do discurso moral de aplicação, o que implica a tese de que tais discursos operam já pressupondo a validade das normas, exatamente o oposto ao que ocorre num discurso de fundamentação. Cabe observar que tanto quanto

45 Cf. GÜNTHER, Klaus. Ein normativer Begriff der Kohärenz für eine Theorie der juristischen Argumentation, p. 167-168.

46 Cf. GÜNTHER, Klaus. Ein normativer Begriff der Kohärenz für eine Theorie der juristischen Argumentation, p. 166.

47 Cf. GÜNTHER, Klaus. Ein normativer Begriff der Kohärenz für eine Theorie der juristischen Argumentation, p. 166.

48 Cf. GÜNTHER, Klaus. Ein normativer Begriff der Kohärenz für eine Theorie der juristischen Argumentation, p. 170.

49 Cf. GÜNTHER, Klaus. Ein normativer Begriff der Kohärenz für eine Theorie der juristischen Argumentation, p. 171-172.

Cf. GÜNTHER, Klaus. Ein normativer Begriff der Kohärenz für eine Theorie der juristischen Argumentation, p. 186-187. 
Alexy, Günther salienta as similitudes entre os dois discursos. Ambos formulam uma pretensão de correção normativa e ambos seguem, na argumentação, alguns princípios, regras e formas que são comuns. No entanto, para ele, a argumentação jurídica só pode manter-se enquanto argumentação discursiva, sob a distinção aplicar/fundamentar, pois alberga condições restritivas ao procedimento discursivo, como limitação de tempo e caráter coativo da decisão. ${ }^{51}$ Compreendida a discursividade jurídica, nos moldes do discurso de fundamentação, e considerando as restrições de tempo e saber, acaba ocorrendo a abolição da discursividade. De fato, todos os princípios, regras e formas da argumentação jurídica carecem da referência ao princípio da universalidade, razão pela qual o discurso jurídico não se perfaz como discurso de fundamentação, pois suas condições restritivas não têm como cumprir as condições exigidas por este. No entanto, como o discurso de aplicação já pressupõe a validade das regras, o discurso jurídico pode constituir-se sob condições restritivas, sem se desqualificar como argumentação. ${ }^{52}$ Portanto, apesar da distância entre o discurso de fundamentação moral e o de aplicação do direito, é possível manter o discurso jurídico de aplicação como um caso especial do discurso moral de aplicação, pois as limitações de ambos mantêm uma similitude que permite salvaguardar a tese do caso especial.

Cabe anotar, também, a crítica dirigida ao que ele nomeia de radicalismo da teoria da coerência de Dworkin. Ela é radical, porque fundamenta também a correção da norma. Günther propõe que ela seja restringida às situações de aplicação e que o juiz Hércules seja substituído por um procedimento discursivo. Dworkin teria elevado a coerência a uma exigência infinita que só pode ser cumprida pelas capacidades super-humanas de Hércules. ${ }^{53}$

Habermas, como visto, salienta a elegância da teoria de Günther, mas acusaa de simplesmente deslocar o sentido da coerência do sistema de direitos. ${ }^{54}$ Ele afirma uma concepção de coerência que se modifica "dependendo da constelação de características relevantes de um caso a ser decidido", 55 o que maltrata a segurança jurídica. ${ }^{56}$ Günther assume essa busca de coerência e distingue fundamentar de aplicar, aliviando a decisão judicial de questões de fundamentação, tomando a validade da norma como pressuposta, como pode ser visto no incidente de constitucionalidade, o qual tem que ser resolvido antes da aplicação do conjunto de normas ao caso concreto. O ponto para Habermas, nas palavras do próprio Günther, é que, para podermos resolver conflitos de normas, "supomos contrafaticamente que todas as normas válidas formam, finalmente, um sistema coerente ideal

51 Cf. GÜNTHER, Klaus. Ein normativer Begriff der Kohärenz für eine Theorie der juristischen Argumentation, p. 184-186.

52 Cf. GÜNTHER, Klaus. Ein normativer Begriff der Kohärenz für eine Theorie der juristischen Argumentation, p. 187-188.

53 Cf. GÜNTHER, Klaus. Ein normativer Begriff der Kohärenz für eine Theorie der juristischen Argumentation, p. 190.

54 Cf. TrFG1 p. 272 [FG p. 268]

55 TrFG1 p. 272 [FG p. 268].

56 Cf. TrFG1 p. 272-3 [FG p. 269]. 
que permite exatamente uma resposta correta - em outras palavras: a razão prática não se contradiz". ${ }^{77}$ Assim, o julgador não se pode furtar a "uma avaliação reconstrutiva das normas tidas como válidas", ${ }^{88}$ do modo como faz Dworkin em sua teoria. No entanto, tal reconstrução avaliativa não pode ser feita nos termos da tese do caso especial, pois, se o sistema jurídico tivesse que ser reconstruído nos termos do discurso moral, a possibilidade de uma justificação racional estaria ameaçada, como já salientado acima, pois a ordem jurídica é "permeada de contingências". 59 Em suma, não pode haver uma estrita separação entre aplicar e fundamentar. ${ }^{60}$

Na formulação que lhe dá Alexy, ${ }^{61}$ válida incluso para o modelo habermasiano, uma teoria do discurso da aplicação tem que dar conta de três tarefas: aaa] correlacionar certeza jurídica e correção; bbb] tornar manifesta a racionalidade presente nos conceitos de coerência, princípio, adequação e paradigma; ccc] salvaguardar uma teoria democrática do Estado. Segundo a tese do caso especial, o discurso prático em geral não inclui apenas argumentos morais, mas também aqueles argumentos que Habermas nomeia como pragmáticos e éticos. O que é especial no discurso jurídico é a sua limitação institucional. Até aqui não se vê no que Alexy e Habermas diferem. No entanto, para Habermas, a entrada de tais argumentos, no mundo jurídico, muda a sua natureza, principalmente os morais, o que para Alexy não acontece, visto que a especialidade se dá pelo caráter substantivo dos argumentos no mundo jurídico. O ponto de Habermas contra Alexy consiste em afirmar que a tese do caso especial não leva a sério o caráter autoritário dos argumentos, no mundo jurídico, tal qual marcado pela sua origem legislativa, introduzindo uma liberdade do julgador que toca perigosamente os limites da separação de poderes.

Habermas, então, faz uma dupla operação: desacopla os discursos jurídicos do mundo dos discursos morais, seja de fundamentação, seja de aplicação, e complexifica a racionalidade jurídica, ampliando o seu escopo para albergar, não só razões morais, mas pragmáticas, éticas, bem como compromissos resultantes de negociação, ${ }^{62}$ um amálgama de validade originado no procedimento democrático de legitimidade. Enfim, a racionalidade jurídica não pode ser equiparada à racionalidade moral, pois "a dimensão de validade mais complexa das normas do direito proíbe equiparar a correção de decisões jurídicas à validade de juízos morais e, nesta medida, considerá-la como um caso especial de discursos morais". 63

57 GÜNTHER, Klaus. Ein normativer Begriff der Kohärenz für eine Theorie der juristischen Argumentation, p. 182.

58 TrFG1 p. 289 [FG p. 285].

59 TrFG1 p. 290 [FG p. 285].

60 Cf. MICHELMAN, Frank I. Family Quarrel, p. 1176

61 Cf. ALEXY, Robert. Jürgen Habermas's Theory of Legal Discourse, p. 1033-1034.

62 Cf. TrFG1 p. 200 s. [FG p. 197 s.].

63 TrFG1 p. 290 [FG p. 286]. 
Ademais, a tese sugere uma falsa subordinação do direito à moral. Para superá-la, é necessário levar a sério as diferenças entre direito e moral, o que pode ser feito concebendo um princípio do discurso abstrato, o qual se especifica em relação a diferentes normas de ação: morais e jurídicas. Com isso, aa] se evita a tese do caso especial, pois discursos jurídicos não precisam ser limitados segundo a lógica dos discursos morais, visto que eles são referidos à legitimidade mais complexa do direito gerado democraticamente. Além disso, bb] evita que discursos jurídicos sejam referidos só a normas jurídicas, pois, por estarem inseridos num sistema de direitos, podem apelar a estratégias argumentativas que compensam suas contingências. Assim, as normas do processo judicial, no âmbito da aplicação do direito, são destinadas a compensar a falibilidade e a incerteza da decisão resultantes do fato de os pressupostos comunicativos idealizados só serem preenchidos aproximadamente. ${ }^{64}$

Ademais, seria estranho, sob o ponto de vista da coerência do sistema de Habermas, que o direito seja concebido como complemento da moral justamente para atenuar a sua insuficiência motivacional, sua fraqueza institucional e, principalmente, sua indeterminação cognitiva e que a moral tenha, agora, que vir em socorro do direito, quando ele não consegue resolver questões de aplicação. Para Habermas, é o contrário que procede, ou seja, é o direito que vem em socorro da moral e não a moral em socorro do direito. A moralização do direito é recusada, não só por uma divisão de trabalho entre ambas, mas porque a moral, dadas as suas exigências, não consegue ofertar uma determinação para a prática.

Manifesta-se, nesse âmbito, a tensão entre faticidade e validade própria do direito: "O conteúdo da tensão entre a legitimidade e a positividade do direito é controlado na jurisdição como um problema da decisão correta e, ao mesmo tempo, consistente". ${ }^{65}$ Tal tensão se renova no próprio processo judicial como a diferença entre as exigências ideais de um procedimento, cujo fim fosse só a busca da correção e as limitações fáticas, como tempo. ${ }^{66}$

Desabrigado do domínio moral, devido à carga de contingência da história, que o direito carrega consigo, e não podendo realizar um procedimento discursivo exigente, devido ao caráter manifestamente interessado da contenda judicial, no caso concreto, Habermas perscruta as ordens processuais como um esteio que possa compensar esses déficits do discurso jurídico: "As ordens dos processos judiciais institucionalizam a prática de decisão judicial de tal modo que o juízo e a fundamentação do juízo possam ser entendidos como um jogo de argumentação" ${ }^{67} \mathrm{O}$ olhar discursivo de Habermas consegue vislumbrar, mesmo que seja obliquamente, um elemento de racionalidade no entrecruzamento entre o ordenamento processual, o desempenho de seus comandos pelo interesse estratégico das partes e a argumentação racional. Para ele, restrições materiais do processo "servem para a delimitação

${ }_{65}$ Cf. TrFG1 p. 291-2 [FG p. 287]

65 TrFG1 p. 292 [FG p. 287]. Segundo Alexy, a questão central da filosofia do direito é como relacionar coerção e correção normativa [Cf. ALEXY, Robert. The Nature of Legal Philosophy, p. 163].

66 Cf. TrFG1 p. 292 [FG p. 287-288].

67 TrFG1 p. 292 [FG p. 288]. 
institucional de um espaço interno para o livre evoluir de argumentos e discursos de aplicação". 68 Portanto, as regras do processo não determinam quais argumentos podem ser aceitos, nem o curso da argumentação. ${ }^{69}$ Tais regras garantem um espaço isento de influências externas, devendo os atores ficar adstritos aos limites da contenda registrada no processo. ${ }^{70}$ Vale aqui o mote: "Ouod non est in processu non est in mundo". De tal forma que

os processos jurídicos cruzam-se com os argumentativos, sendo que a instauração jurídico-processual de discursos jurídicos não pode intervir no âmago da lógica da argumentação. O direito processual não regula a argumentação jurídico-normativa enquanto tal, porém assegura, numa linha temporal, social e material, o quadro institucional para decorrências comunicativas não-circunscritas, que obedecem à lógica de discursos de aplicação. ${ }^{71}$

Nessa perspectiva, ele analisa determinações do processo civil e penal - como prazos, igualdade das partes, definição do objeto de disputa, colheita de provas ao modo agonístico como litigância entre as partes que perseguem seus próprios interesses $^{72}$ - no sentido da realização de uma atividade legitimamente argumentativa, ao menos sob perspectiva do olhar imparcial do juiz, como visto acima.

E.g., tal racionalidade pode ser vislumbrada nos dispositivos seguintes, dentre outros, do sistema processual brasileiro:

- $\quad$ a Constituição da República Federativa do Brasil, em seu art. 5o, LIV, estabelece que "ninguém será privado da liberdade ou de seus bens sem o devido processo legal"; ${ }^{73}$ no inciso LV, estatui como direito individual o contraditório e a ampla defesa, e no art. 93, III, ordena que todas as decisões judiciais sejam fundamentadas, sob pena de nulidade;

- $\quad$ o $C P P,{ }^{74}$ no art. 157, preceitua: "O juiz formará sua convicção pela livre apreciação da prova". O art. 381, III, estabelece que a sentença deve conter "a indicação dos motivos de fato e de direito em que se fundar a decisão";

- $\quad$ o $\mathrm{CPC}^{75}$ esculpiu no art. 131: "O juiz apreciará livremente a prova, atendendo aos fatos e circunstâncias constantes dos autos, ainda que não alegados pelas partes; mas deverá indicar, na sentença, os motivos que lhe formaram o convencimento". No art. 192, preceitua que os prazos peremptórios não podem ser reduzidos ou prorrogados pelas partes. O art. 286 ordena que o pedido de-

68 TrFG1 p. 293 [FG p. 289].

69 Cf. TrFG1 p. 294 [FG p. 290].

70 Cf. TrFG1 p. 295 [FG p. 290-291].

71 TrFG1 p. 292 [FG p. 288].

2 "O levantamento de provas não está estruturado discursivamente no sentido de uma busca cooperativa da verdade [... no entanto] os espaços de ação estratégicos estão organizados de tal forma que possivelmente todos os fatos relevantes [...] são tematizados" [TrFG1 p. 293 [FG p. 289]].

73 Evidentemente, a prisão em flagrante se constitui numa exceção a esse comando. Para esse caso, no entanto, a mesma Constituição, no inciso LXII, ordena que tal prisão e o local onde o preso se encontrar "serão comunicados imediatamente ao juiz competente", para que, então, decida fundamentadamente.

74 Cf. BRASIL. Decreto-Lei 3.689, de 3 de outubro de 1941. Código de Processo Penal.

75 Cf. BRASIL. Lei 5.869, de 11 de janeiro de 1973. Código de Processo Civil. 
ve ser certo ou determinado, estabelecendo os casos em que o mesmo pode ser genérico ${ }^{76} \mathrm{O} 331, \S 2^{\circ}$, estatui que, não obtida a conciliação no processo, "o juiz fixará os pontos controvertidos, decidirá as questões processuais pendentes e determinará as provas a serem produzidas".

Ademais, no processo judicial, a relação circular entre normas jurídicas e estados de coisa é atenuada pela estratégia de deixar as normas nos bastidores para estabelecer os fatos, através da separação entre questões de fato e de direito. Colhem-se a prova e os fatos, os quais são avaliados juridicamente num segundo momento. Nesse segundo momento, o juiz que decide desinteressadamente, tem que fundamentar suas decisões perante os participantes do processo, embora com força coativa. Ele decide, num vácuo processual, segundo seu livre convencimento motivado, ${ }^{77}$ tendo em vista, inclusive, a possibilidade de recurso.

Por fim, os tribunais superiores têm que manter a coerência da ordem jurídica no seu todo. No sistema brasileiro, o Superior Tribunal de Justiça cumpre esse requisito. De fato, um dos fatores que possibilitam o recurso especial ao Tribunal acontece, quando a decisão recorrida "der à lei federal interpretação divergente da que lhe haja atribuído outro tribunal". ${ }^{78}$ Evidentemente, o Supremo Tribunal Federal cumpre função análoga, através do recurso extraordinário, visto que uniformiza a jurisprudência em face da Constituição da República Federativa do Brasil. $^{79}$

\section{Da réplica de Alexy}

Em defesa da tese do caso especial milita a seguinte argumentação de Alexy. Se os direitos básicos, normalmente os direitos humanos, traduzem determinações normativas que limitam o próprio conteúdo das decisões do legislativo, então o direito porta uma conexão com a correção das normas em geral. Portanto, hão que se distinguir duas dimensões na argumentação legal: aquela da coação da autoridade, e aquela da validade discursiva, a qual é livre, aberta e não-autoritativa como a anterior. Ou seja, o raciocínio jurídico é mais do que subsunção e mais do que seu caráter de autoridade, pois conecta com uma textura aberta de normatividade. Todos podem criticar decisões legais com argumentos. Tal crítica pode levar a que a decisão seja revista no segundo grau ou a que um outro juízo decida diferentemente. Uma teoria da argumentação legal deve cobrir ambos os lados. A tese do caso especial [Sonderfallthese] visa a isso, ao estabelecer que o discurso jurídico é um caso especial do discurso prático em geral. Isso, em resumo, porque o discurso jurídico concerne ao obrigatório, permitido, proibido, portanto, ao prático, e porque pretende correção, não uma correção absoluta, mas aquela dentro de uma ordem legal que é autoritativa. ${ }^{80}$

\footnotetext{
76 Quais sejam: I - nas ações universais, quando não for possível individuar os bens, como na petição de herança; II - quando não for possível determinar definitivamente as conseqüências do ato ou fa77 to ilícito; III - quando o valor depender de ato que deva ser praticado pelo réu.

77 Cf. TrFG1 p. 295 [FG p. 290-1].

78 BRASIL. Constituição da República Federativa do Brasil, promulgada em 05.10.1988. Art. 105, III, c.

${ }_{80}$ Art. 102, III, a.

Cf. ALEXY, Robert. The Special Case Thesis, p. 375.
} 
O problema da tese do caso especial é o genus proximum dela, ou seja, o que se entende por discurso prático em geral. Se este último for interpretado como discurso moral, então a tese do caso especial está errada, pois o discurso jurídico está aberto também a razões ético-políticas e pragmáticas. Porém, o discurso prático em geral não é o mesmo que discurso moral. O discurso prático em geral se diferencia do discurso jurídico, não por ser moral, mas pelo seu caráter livre, não-autoritativo. Ou seja, não é um discurso de razões institucionais baseadas na lei, nos precedentes e na jurisprudência. ${ }^{81}$

Para Alexy, o discurso prático geral é mais complexo do que o conjunto de normas estritamente morais pretendido por Habermas. É complexo, porque "o justo é permeado pelo bem" ${ }^{82}$ Isso é evidente, se não se reduzir o justo ao discurso dos direitos humanos. Ou seja, se a justiça incluir também questões de distribuição e retribuição, como parece realmente incluir em vários modelos, como o de Habermas ou de Alexy, então questões do Estado de bem-estar social ou da pena são também questões de justiça. Nesses argumentos, o auto-entendimento do indivíduo e da comunidade é importante e é uma questão de bem. Portanto, o discurso prático em geral não é uma simples mistura ou combinação, mas uma conexão necessária expressando a unidade da razão prática. Essa é a base da tese do caso especial. ${ }^{83}$

Em sua crítica à tese do caso especial, Habermas defendeu que argumentos práticos gerais mudam seu caráter ou natureza, quando empregados em contextos jurídicos, pois eles são "revestidos com um outro modo de validade" ${ }^{84}$ ou seja, "conteúdos morais, na medida em que são traduzidos para o código do direito, passam por uma transformação jurídica de seu significado". ${ }^{85}$

A réplica de Alexy tem base no questionamento dessa metamorfose que os conteúdos sofreriam ao adentrarem no campo do direito: "A questão é se argumentos morais como também outros argumentos do discurso prático em geral realmente mudam o seu caráter ou natureza tão essencialmente quando empregados em argumentos legais, de tal forma que rompem com a tese do caso especial" ${ }^{86}$

Assim, Habermas atribui duas pressuposições à tese do caso especial, que não se conectam necessariamente com a tese do caso especial segundo Alexy. ${ }^{87}$ A primeira é nominada por ele como a presunção do subconjunto. De fato, afirma Habermas: "Discursos legais não constituem casos especiais de argumentações morais, ligados ao direito vigente, limitados, por isso, a uma parte [Teilmenge] daquilo que é moralmente permitido ou necessário. Eles são, ao invés disso, referidos naturalmente ao direito gerado democraticamente" ${ }^{88}$ Disso Habermas con-

81 Cf. ALEXY, Robert. The Special Case Thesis, p. 378.

82 Cf. ALEXY, Robert. The Special Case Thesis, p. 379

83 Cf. ALEXY, Robert. The Special Case Thesis, p. 379

84 TrFG1 p. 256 [FG 253].

85 TrFG1 p. 254 [FG 250].

86 ALEXY, Robert. The Special Case Thesis, p. 380

87 Cf. ALEXY, Robert. The Special Case Thesis, p. 380-381.

88 TrFG1 p. 292 [FG p. 287]. 
clui que discursos legais seriam, segundo a tese do caso especial, discursos morais. Para Alexy, isso é um equívoco, visto que discursos legais são integrados com argumentos práticos gerais. Portanto, trata-se de integração, não de subconjunto.

A segunda, ele nomeia como presunção da especificação. Nesse particular, Habermas imputa a Alexy ter que mostrar que as regras processuais jurídicas "apenas especificam as condições gerais do processo de discursos práticomorais em relação à ligação com o direito vigente". ${ }^{89}$ Ele imputa a Alexy a nãosatisfação desse requisito. No entanto, replica Alexy, nos discursos jurídicos, algumas regras correspondem àquelas do discurso prático em geral, embora nem todas correspondam, visto que discursos jurídicos se definem pelo emprego de argumentos de autoridade, razão pela qual nem todas as regras dos discursos jurídicos podem ser casos especiais das regras do discurso prático em geral. Ou seja, a tese da especificação completa seria incompatível com o caráter coativo do direito.

Alexy pensa ser possível a defesa da tese do caso especial, evitando essas pressuposições. Ele imputa a conclusão habermasiana da metamorfose dos conteúdos morais, que adentram no mundo jurídico, ao caráter coativo do direito, o qual induz a pensar, equivocadamente, que a argumentação jurídica seja qualitativamente diferente do discurso prático em geral. Por seu turno, em resposta ao desnível existente entre as exigências da racionalidade moral e da jurídica esta última marcada pelas vicissitudes da política, visto que o direito tem origem no órgão político do Estado -, desnível que, para Habermas, implicaria a impossibilidade de realizar o discurso jurídico racionalmente - Alexy replica que a tese do caso especial não defende que sempre haja, ou seja atual, a "harmonia entre direito e moral", ${ }^{90}$ mas que ela é uma pretensão implícita, de tal forma que uma decisão moralmente errada seria também legalmente defeituosa. ${ }^{91} \mathrm{Na}$ verdade, a tese de Alexy é que uma norma ou decisão jurídica moralmente errada é defeituosa, no sentido de não ser uma norma jurídica tout court. ${ }^{92} \mathrm{Um}$ sistema de normas, que não pretendesse correção, não seria um sistema legal. Como exemplo, imagine que o primeiro artigo da Constituição da República Federativa do Brasil estabelecesse: a República Federativa do Brasil se baseia na injustiça e na desigualdade. Tal sistema para Alexy não seria um sistema jurídico. Ou, então, o seguinte exemplo de decisão judicial: condeno o acusado à morte, o que é errado. Tal decisão se desqualificaria como decisão judicial.

Ou seja, para ele, a integração de argumentos práticos gerais, no contexto de argumentos jurídicos, não pode mudar radicalmente o seu caráter ou nature-

89 TrFG1 p. 288-9 [FG p. 284].

90 TrFG1 p. 289 [FG 284].

91 Cf. ALEXY, Robert. The Special Case Thesis, p. 382

92 Cf. ALEXY, Robert. The Argument from Injustice. A Reply to Legal Positivism. [B. L. Paulson and S. L. Paulson: Begriff und Geltung des Rechts], p. 40. 
za como propalado por Habermas. ${ }^{93}$ De fato, se mudarem o caráter e a natureza, nessa passagem [integração] da argumentação prática geral para a argumentação jurídica, então o discurso prático em geral não pode ser o genus proximum de discursos jurídicos. ${ }^{94}$ No entanto, tal integração pode ser concebida de dois modos. ${ }^{95}$ Seja numa versão coerentista, por exemplo, o holismo legal, segundo o qual todas as premissas estão no sistema legal e necessitam apenas ser descobertas. Isso é demais exigente e sobrecarrega a jurisdição profissional, implicando, inclusive, total autonomia normativa ao direito. No entanto, toda fórmula para precisar essa idéia prova ser dependente de valores ou normas externas ao sistema. É a intuição hermenêutica da circularidade entre pré-compreensão e texto, norma e fato. ${ }^{96}$ Nessa versão, a tese do caso especial parece sucumbir à imputação habermasiana de uma diferença de nível entre a exigência dos argumentos morais e a realização jurídica dos mesmos. Seja numa versão processual, segundo a qual "argumentos práticos gerais são argumentos não-institucionais", ${ }^{97}$ de tal forma que tais argumentos podem circular por todas as esferas, inclusa a do direito, sem mudar essencialmente seu caráter de ser livre e não de autoridade. Essa é uma das razões básicas para a tese do caso especial, não sucumbindo à alegada dificuldade mencionada anteriormente.

\section{Da tréplica de Habermas}

Em sua tréplica, Habermas, ${ }^{98}$ - apesar de dizer que ele e Alexy habitam numa casa comum -, argumenta não ter claro o papel desempenhado pelo que Alexy chama de discurso prático geral. Na verdade, como visto, tais argumentos misturam, de alguma forma, os mesmos elementos que Habermas amalgama na legitimidade do direito, ou seja, razões morais, éticas, pragmáticas. O ponto central da réplica de Alexy reside na diferença apontada entre os discursos morais e jurídicos, ou seja, a estes ele atribui o caráter institucional e coativo, àqueles o caráter livre. Ora, pela tese do caso especial, tais argumentos "passeiam" pela argumentação jurídica - visto este portar uma dimensão de validade que vetorializa em direção a seu exterior -, sem mudar substantivamente a sua natureza, ou seja, seu caráter livre. Mais que isso, nos casos difíceis, "razões morais podem e devem participar na justificação de decisões legais, quando razões jurídicas não estão

93 De fato, Habermas afirma que os conteúdos morais são "revestidos com um outro modo de validade" [TrFG1 p. 256 FG 253], que eles "passam por uma transformação jurídica de seu significado" [TrFG1 p. 254 FG 250]. Nesse sentido, ele defende uma "dimensão de validade mais complexa das normas do direito" [TrFG1 p. 290 FG 286].

94 Cf. ALEXY, Robert. The Special Case Thesis, p. 383

95 Cf. ALEXY, Robert. The Special Case Thesis, p. 383-384

96 "Just as norms cannot apply themselves, a legal system as such cannot produce coherence" ALEXY, Robert. The Special Case Thesis, p. 383

97 "General practical arguments are non-institutional arguments" [ALEXY, Robert. The Special Case 98 Thesis, p. 384].

98 Cf. HABERMAS, Jürgen. A Short Reply, p. 447. 
disponíveis" ${ }^{99}$ Assim, pode-se vislumbrar que Alexy consiga responder a uma das objeções de Habermas, qual seja, àquela do descompasso entre moral e direito, mas não à objeção de maltratar a segurança jurídica. De fato, se tal argumentação é marcada pelo seu caráter livre, podendo o juiz adentrar nela, sem rodeios, nas suas argumentações jurídicas, então a segurança fica ameaçada. Ademais, se ao juiz for permitido arrazoar em termos de discurso prático em geral, a linha divisória da separação de poderes fica também ameaçada. Para Habermas, o judiciário tem que ficar adstrito ao amálgama de razões construído pelo legislativo durante o processo de positivação das normas: "A justiça só pode mobilizar as razões que lhe são dadas" ${ }^{100}$ Assim, o que o judiciário está autorizado a fazer é reconstruir, em outros termos, os mesmos argumentos, mas não trazer para o direito argumentos que já não estejam na legitimidade do ordenamento, oriundos do processo democrático de legitimidade do direito. Ou seja, em nome da segurança jurídica e do respeito à divisão de poderes, há que se manter o caráter coativo do direito, no sentido de restringir a argumentação ao conjunto de argumentos positivados no ordenamento, através do processo democrático. Não custa relembrar que essa é a razão pela qual Habermas se interessa pela proposta da interpretação construtiva de Dworkin a partir de princípios.

Com isso, Habermas delimita melhor em que sentido as normas procedimentais coativas se entrecruzam com a argumentação jurídica. Tal se dá pelo caráter jurídico de tal argumentação. Ou seja, ela não pode ser aberta no mesmo sentido dos argumentos morais que são absolutamente livres para discutir todos os aspectos, todos os pontos de vista, todos os argumentos, sendo inclusivos de todos os possivelmente afetados. Não, os argumentos jurídicos têm que ficar adstritos ao amálgama de razões legislado, implicando uma certa clausura da argumentação jurídica, necessária em razão da divisão de poderes e, portanto, como condição de possibilidade de legitimidade democrática do próprio judiciário, o qual não pode operar independentemente dos órgãos e procedimentos que providenciam a única garantia da legitimidade democrática.

\section{Incoerências na posição de Habermas?}

Em FG, Habermas se posiciona contra dois pontos defendidos por Alexy. Um foi aquele apresentado, acima, sobre a tese do caso especial, e o outro concerne à doutrina da ponderação. Como visto, sua crítica àquela presume

- que o direito não esteja numa relação de subordinação à moral, mas de complentaridade; ${ }^{101}$

- que o direito não possa contrariar a moral; ${ }^{102}$

- que se deva levar a sério a distinção entre direito e moral; ${ }^{103}$

99 ALEXY, Robert. The Nature of Legal Philosophy, p. 165.

100 TrFG2 p. 183 [FG p. 529].

101 TrFG1 p. 140-1 [FG p. 137].

102 TrFG1 p. 140-1 [FG p. 137].

103 TrFG1 p. 291 [FG p. 286-287]. 
- $\quad$ que o elemento construtivo apareça com mais força no direito do que na moral, no seu conteúdo [teleológico v. deontológico], no seu sentido de validade [Gültigkeit v. Geltung] e no modo de legislação [Einverständnis v. Vereinbarung]; ${ }^{104}$

- que os conteúdos morais, ao serem traduzidos para o código jurídico, sejam revestidos com um outro modo de validade; ${ }^{105}$

- $\quad$ que os "conteúdos morais, na medida em que são traduzidos para o código do direito, passem por uma transformação jurídica de seu significado"; ${ }^{106}$

- $\quad$ que o princípio do discurso seja neutro em relação ao direito e à moral, apesar de seu conteúdo normativo comum, a saber, a imparcialidade. ${ }^{107}$

Na crítica à doutrina da ponderação, Habermas se volta contra a doutrina dos valores da corte constitucional alemã [Wertordnungslehre], aplicada principalmente aos recursos constitucionais em geral, ${ }^{108}$ a qual foi teorizada por Alexy, através do princípio da ponderação. Ele imputa à teoria de Alexy o desfazimento da distinção entre princípios e valores, estes entendidos como prescrições de otimização, cuja intensidade permanece aberta. A equiparação de princípios a valores permite a Alexy construir a doutrina da ponderação de valores [Güterabwägung]. A crítica de Habermas é, resumidamente, que a assimilação de princípios a valores confunde dois conceitos distintos, ${ }^{109}$ na medida em que aqueles têm validade deontológica e estes, validade teleológica. Ao equiparar uns e outros, Alexy acusa Habermas - faz ruir a viga mestra [Brandmauer] que dá prioridade ao justo sobre o bem no discurso jurídico. ${ }^{110}$ Além disso, a ponderação introduz arbitrariedade na aplicação. Nesse diapasão ele afirma:

normas e princípios possuem uma força de justificação maior do que a de valores, uma vez que podem pretender, além de uma especial dignidade de preferência, uma obrigatoriedade geral, devido ao seu sentido deontológico de validade; valores têm que ser inseridos, caso a caso, numa ordem transitiva de valores. E, uma vez que não há medidas racionais para isso, a avaliação realiza-se de modo arbitrário ou irrefletido, seguindo ordens de precedência e padrões consuetudinários. ${ }^{111}$

Assim, aquilo que ele defende, para se posicionar contra a tese do caso especial, ele parece ter que negar em sua crítica à doutrina da ponderação. A esse respeito, comentando a tradução da moral ao direito, há pouco mencionada, Teubner afirma: "Ele parece subestimar o efeito simplificador dessa tradução,

$\overline{104}$ Cf. TrFG1 p. 192-7 [FG p. 189-194].

105 TrFG1 p. 256 [FG p. 252-253].

106 TrFG1 p. 254 FG p. 250]

107 TrFG1 p. 142 [FG p. 138].

108 Trata-se daqueles recursos que versam sobre decisões que contrariam dispositivos da Constituição, sem declarar a inconstitucionalidade de norma ou ato administrativo, como é o caso, na Constituição Brasileira, do art. 102, III, a.

109 Cf. FG p. 310-1 [TrFG1 p. 316].

110 Cf. FG p. 315 [TrFG1 p, p. 321]. O debate entre Alexy e Habermas sobre a teoria da ponderação defendida pelo primeiro pode ser acompanhada nos seguintes artigos posteriores a FG: ALEXY, Robert. Jürgen Habermas's Theory of Legal Discourse, p. 1027-34; ALEXY, Robert. Constitutional ${ }_{111}$ Rights, Balancing, and Rationality, p. 131-140; HABERMAS, Jürgen. A Short Reply, p. 445-453.

111 TrFG1 p. 321 [FG p. 315-316]. 
quando ele, em sua polêmica contra a teoria de Alexy da ponderação de bens, insiste em que, na prática legal, a diferença entre princípios deontológicos e valores teleológicos precisa ser respeitada". ${ }^{112} \mathrm{O}$ ponto de Teubner é que o tratamento da distinção entre moral e direito em Habermas é incompatível com a crítica da doutrina da ponderação. No entanto, como os mesmos fundamentos alegados por Teubner são aqueles usados para criticar a tese do caso especial, se torna plausível o tipo de apontamento que se está sugerindo aqui com relação aos dois posicionamentos de Habermas. Portanto, parece que o que ele nega na tese do caso especial, ele precisa afirmar para criticar a ponderação; que o que ele admite na tese da ponderação depõe contra a sua crítica à tese do caso especial.

Na sua resposta a Teubner, Habermas parece cair mesmo em sua armadilha, de tal forma que, para salvar a crítica à doutrina da ponderação, ele parece se alistar nas fileiras da tese do caso especial:

Direito e moralidade obedecem ao mesmo princípio discursivo e seguem a mesma lógica discursiva na aplicação e justificação. O direito não é distinguível da moral através da questão abstrata de como conflitos interpessoais devem ser regulados no igual interesse de todos, nem através das regras de argumentação fornecidas pela universalização e adequação. A diferença específica que separa direito de moral jaz, não no discurso, mas no fato de que regras justificadas e aplicadas discursivamente têm a forma legal, i. é, são decretadas politicamente, interpretadas de maneira coativa e cumpridas com a ameaça da sanção do Estado. [...] Essas propriedades do código legal clamam por uma "tradução" dos vários argumentos - pragmáticos, éticos e morais - e compromissos. ${ }^{113}$

Como não ver aqui uma incongruência entre o empreendimento de FG e a afirmação de que moral e direito "seguem a mesma lógica discursiva"? Ora, em FG, são estabelecidos o princípio de universalização e o princípio da democracia. Ademais, a afirmação de que direito e moral não se distinguem, "através da questão abstrata de como conflitos interpessoais devem ser regulados", também depõe contra a dicção de uma racionalidade mais complexa do direito em FG. Se moral e direito se distinguem apenas pela coerção, então não se vê como o direito não esteja subordinado à moral. Aqui ele parece ser vitimado pela mesma crítica que ele havia endereçado a Kant, em razão de este ofertar uma validade moral para o direito:

Subjaz a essa construção a idéia platônica segundo a qual a ordem jurídica copia e, ao mesmo tempo, concretiza no mundo fenomenal a ordem inteligível de um "reino dos fins". Mesmo que não se leve em conta a metafísica kantiana, é evidente que na reduplicação do direito em direito natural e positivo perdura uma herança platônica, a saber, a intuição segundo a qual a comunidade ideal dos sujeitos moralmente imputáveis - a comunidade de comunicação ilimitada, de Josiah Royce até Apel - entra no tempo histórico e no espaço social, passando pelo medium do direito, adquirindo uma figura concreta, localizada no espaço e no tempo, enquanto comunidade de direito. ${ }^{114}$

$\overline{112}$ TEUBNER, Gunther. De Collisione Discursuum: Communicative Rationalities in Law, Morality, and Politics, p. 914

113 HABERMAS, Jürgen. Reply to Symposium Participants, Benjamin N. Cardozo School of Law, p. 1538.

TrFG1 p. 140[FG p. 136-137]. 
Como resolver isso?

Primeiro, direito e moral são distintos, sob vários aspectos, mas não separados: "A legitimidade do direito não deve ser assimilada à validade moral, nem deve o direito ser separado completamente da moral". ${ }^{115}$ Assim, é possível fazer valer um aspecto ou outro da relação tensa entre faticidade e validade contra uma posição ou outra, o que não significa, com isso, que se esteja negando o outro aspecto. Para Habermas, a faticidade pode albergar a mais injusta das regras, como a escravidão, sem desqualificá-la como regra jurídica, bem como a mais válida das regras como a proibição do racismo, sem ferir o seu caráter moral e o seu caráter legal. Assim, contra a ponderação, a prioridade do justo não significa a moralização do direito - embora a resposta de Habermas pareça tê-lo comprometido com tal conseqüência - significa, sim, que os conteúdos morais que adentraram no direito devam ter prioridade sobre as demais razões que também adentraram nele. Vale lembrar: o direito não pode contradizer normas morais. Assim, parece que Habermas não precisaria ter concedido tanto quanto sua resposta concedeu para responder a Teubner, pois a resposta parece negar os termos de FG.

Segundo, quanto à tese do caso especial, o próprio Habermas afirma tratar-se de fazer uma limpeza na casa habitada por ambos. ${ }^{116}$ Ao que parece, o ponto reside numa questão de forma e não de conteúdo. Alexy propõe que a abertura da racionalidade moral adentre no direito em toda a sua abrangência e liberdade, qualificada pelo seu caráter inclusivo de perspectivas, argumentos, informações, próprio do discurso moral. ${ }^{117}$ Habermas, por sua vez, quer circunscrever o direito à racionalidade cristalizada nos produtos da atividade legislativa, vedada aquela liberdade do juízo característica da abertura à universalidade da moral. O direito não é só autoritativo, como pensa Alexy, no sentido da coação, do tempo, da jurisprudência, mas do caráter dogmático dos argumentos que o legislador preceituou [Geltung]. A diferença entre eles é tênue, pois ambos partem do fato de que os ordenamentos jurídicos incorporaram, senão todos os direitos humanos, ao menos boa parte deles. Assim, grande parte da argumentação moral já está no sistema jurídico. A questão que remanesce é como determinar os efeitos desses argumentos dentro do ordenamento, no que concerne à sua configuração. Hoje em dia, parece ser difícil encontrar uma norma que seja injusta do ponto de vista moral, e que não possa ser resolvida pelos argumentos normativos já preceituados no ordenamento jurídico. Mesmo assim, dois exemplos podem ilustrar a dificuldade envolvida.

Concernente à proteção legal do feto, a legislação brasileira estabelece um conjunto de proposições difíceis de serem harmonizadas, principalmente se tivermos em conta as relações entre três diplomas normativos. No nível constitucional,

\footnotetext{
115 HABERMAS, Jürgen. "Between Facts and Norms": an Author's Reflections, p. 939.

116 Cf. HABERMAS, Jürgen. A Short Reply, p. 447.

117 Cf. DUTRA, Delamar José Volpato. Da revisão do conceito discursivo de verdade em "Verdade e justificação", p. 229-230.
} 
e vale lembrar que a Constituição da República Federativa do Brasil data de 1988, é estabelecida a inviolabilidade do direito à vida [art. 5ㄴ, caput], porém, sem a determinação do momento em que tal direito tem começo. O Código Civil de 2002 estabelece no art. $2^{\circ}$ que "a personalidade civil da pessoa começa do nascimento com vida", embora o art. 20. ponha a salvo os direitos do nascituro, desde a concepção, e o art. 1.596, IV, ao determinar que os embriões excedentários, decorrentes de concepção artificial homóloga, presumem-se concebidos na constância do casamento, estabelece direitos patrimoniais aos embriões. Já, o Código Penal, que data de 1940, estabelece o crime de infanticídio com pena de dois a seis anos [art. 123]. O crime de aborto provocado por terceiro tem pena de três a dez anos, quando não houver consentimento da mãe [art. 125], e entre um a quatro anos, quando houver [art. 126]. O crime de aborto provocado pela gestante ou com seu consentimento tem pena de um a três anos [art. 124]. Considerando que o crime de homicídio simples tem pena entre 6 e 20 anos [art. 121], dá para perceber uma clara distinção entre a valorização da vida do feto e de alguém após o nascimento. Isso, sem levarmos em conta o art. 128, que estabelece dois casos em que não se pune o aborto praticado por médico: quando resultar de estupro e em caso de necessidade.

Duas considerações seriam possíveis aqui. Poderia o Judiciário ampliar o rol dos casos de aborto, por exemplo, para incluir a anencefalia? O STJ, em recente decisão, foi no sentido contrário: "O habeas corpus foi impetrado em favor do nascituro, ora no oitavo mês de gestação, contra decisão do Tribunal a quo que autorizara intervenção cirúrgica na mãe para interromper a gravidez. Essa cirurgia foi permitida ao fundamento de que o feto padece de anencefalia, doença que levaria à inviabilidade de sua vida pós-natal. A Turma, porém, concedeu a ordem, pois a hipótese em questão não se enquadra em nenhuma daquelas descritas de forma restrita no art. 128 do CP. Assim, não há como se dar interpretação extensiva ou analogia in malam partem; há que se prestigiar o princípio da reserva legal”. ${ }^{118}$ A segunda observação seria considerar inconstitucionais os casos, não só de permissão do aborto, como das penas diferenciadas para os crimes conexos, em razão do preceito constitucional esculpido no art. $5^{\circ}$, caput, concernente à igualdade e ao direito à vida.

É difícil dizer como a teoria de Habermas responderia a tais colocações. Com relação ao aborto, Habermas o aloca nas fileiras do desacordo moral, visto que seu tratamento se liga a doutrinas abrangentes, tendo como conseqüência a sua resolução no direito à igual liberdade de todos escolherem a sua concepção de vida boa. Habermas sugere aceitar a posição de Dworkin, com relação à questão. ${ }^{119}$ Ora, Dworkin trata do aborto não só ligado ao direito à privacidade protegida pelo devido processo, argumento da Suprema Corte americana, em Roe v. Wade, mas

\footnotetext{
118 HC 32.159-RJ, Rel. Min. Laurita Vaz, julgado em 17/2/ 2004 [Informativo de Jurisprudência do STJ 119 n. 0199, 16 a 20 de fev. de 2004].

119 Cf. HABERMAS, Jürgen. A Short Reply, p. 447.
} 
ligado à liberdade religiosa. ${ }^{120}$ Ele filia o tratamento do aborto como matéria pertencente ao conteúdo da religião, uma doutrina abrangente na formulação de Habermas. De fato, Dworkin entende a crença sobre o valor intrínseco da vida humana como "essencialmente uma crença religiosa", visto que "a religião responde aos mais terríveis aspectos da vida humana". ${ }^{121}$ As decisões sobre procriação têm conotação religiosa, pois tocam nas questões mais importantes da vida humana. No entanto, o problema com relação às religiões é que as opiniões sobre o valor intrínseco são variadas e díspares, pela razão mesma de estarem coladas com formulações religiosas.

Quiçá, a possível falha do argumento de Dworkin e de Habermas poderia residir na fácil aceitação do fracasso filosófico em determinar um argumento para a defesa da atribuição de direitos ao feto e, por conseqüência, remeter a matéria para o domínio das concepções religiosas, metafísicas ou daquilo que Rawls chamava de concepções de bem, com o conseqüente aporte liberal da impossibilidade de o Estado se pronunciar sobre tais conteúdos. Ora, durante muito tempo, houve desacordo moral sobre a escravidão, a exemplo da argumentação aristotélica na Política, ou mesmo sobre a tortura e, nem por isso, a história moral caminhou no sentido de um reenfeitiçamento dessas questões. Ao contrário, elas adentraram no domínio das regras de justiça. Talvez essa situação com relação à vida pré-natal se deva à hipossuficiência e vulnerabilidade dos fetos em fazer valer seus direitos na comunidade de comunicação. Como argumentou Ely: "Fetos não sentam em nossas legislaturas". ${ }^{122}$ Ou seja, é fácil exterminar quem não se pode ver e quem não pode fazer revolução. Além disso, o critério para atribuir direitos a partir da vida consciente, como faculdade de sentir dor, é um critério utilitarista que não pode pretender um privilégio maior frente a outros critérios, como o nascimento, no caso brasileiro, a nidação, no caso alemão ${ }^{123}$, a fecundação no caso católico.

O critério para classificar um assunto no âmbito da concepção de bem não deveria ser o fato do pluralismo, mas se fere direitos de outros. Assim, no caso do aborto, seja como for, na dicção de Ely, há mais do que o corpo da mãe envolvido na decisão: o feto pode não ser uma pessoa, mas nada ele não é. ${ }^{124}$ Ademais, no controle de constitucionalidade, Habermas recepciona a teoria de Ely, segundo a qual a decisão em Roe está equivocada. ${ }^{125}$ Para Ely, é muito mais plausível considerar os fetos como minorias insulares do que as mulheres.

O casamento homossexual seria um outro exemplo a ser considerado. Veja-se a legislação a respeito. A Constituição da República Federativa do Brasil, no art. 226, não define o casamento como a união entre homem e mulher, embora o § $3^{\text {o }}$ defina a união estável como a relação entre homem e mulher. Uma possibilidade de interpretação da Constituição seria que ela não veda o casamento homosse-

${ }_{121}^{120}$ Cf. DWORKIN, Ronald. Freedom's Law: the Moral Reading of the American Constitution, p. 110.

121 DWORKIN, Ronald. Freedom's Law: the Moral Reading of the American Constitution, p. 100.

122 ELY, John Hart. The Wages of Crying Wolf: A Comment on Roe v. Wade, p. 933.

123 Segundo decisão do Tribunal Constitucional Federal [Cf. ZmN p. 56, nota].

${ }_{125}$ Cf. ELY, John Hart. The Wages of Crying Wolf: A Comment on Roe v. Wade, p. 931.

125 Cf. ELY, John Hart. The Wages of Crying Wolf: A Comment on Roe v. Wade, p. 920-949. 
xual. Assim, tendo em vista o estabelecido no art. 5ำ, caput, que todos são iguais perante a lei, "sem distinção de qualquer natureza" e que um dos objetivos da República Federativa do Brasil, no art. 3ํ, IV, é "promover o bem de todos, sem preconceitos de origem, raça, sexo, cor, idade e quaisquer outras formas de discriminação", não seria nonsense pensar o casamento como sendo mais universal do que a união estável. Por outro lado, o Código Civil de 2002, no art. 1.517, estabelece que podem casar o homem e a mulher. Frente a esse quadro, duas alternativas são possíveis:

- a norma constitucional em questão é de eficácia contida, podendo ser restringida por lei, o que tornaria o dispositivo civilista constitucional;

- $\quad$ tendo em vista o conjunto da Constituição, a norma é de eficácia plena, podendo a lei regulamentá-la, mas não restringi-la, o que tornaria o dispositivo civilista inconstitucional.

Em ambos os exemplos, há uma outra possibilidade a ser considerada, qual seja, que deva ser resolvida por via legislativa. Nesse sentido, Ely defende que o aborto deva ser regido por meio legislativo, pois não se trata de uma questão envolvendo a democracia, mas de um valor substantivo da sociedade. Dworkin, por sua vez, afirma que a questão do aborto está fora da competência legislativa, por dizer respeito à igualdade. Negar o aborto significaria, para ele, impor a concepção de bem da maioria sobre o aborto. Nesse ponto, Habermas, como dito, parece ficar com a posição de Dworkin, embora recepcione a teoria de Ely.

No caso dos homossexuais, Ely está disposto a lhes atribuir o epíteto de minoria insular e vítimas de estereótipo, o que permitiria a atividade judiciária sobre o assunto. Dworkin, por sua vez, afirma que questões homossexuais são uma questão de moralidade privada, permitindo o controle judicial de imposições de uma dada concepção de bem sobre o assunto. Nesse ponto, Habermas pareceria concordar com Dworkin e Ely.

Um ponto da teoria de Habermas é que o direito pode regrar questões de valor, desde que tal regramento, no dizer de Dworkin, não implique abandonar o senso do igual valor, ${ }^{126}$ como, por exemplo, na imposição de uma religião ou na criminalização do homossexualismo. Assim, com relação ao casamento de homossexuais, pareceria autorizada uma competência legislativa plena. Como se pode perceber, é difícil vislumbrar uma resposta nos termos da teoria proposta por Habermas.

\section{Referências}

ALEXY, Robert. Jürgen Habermas's Theory of Legal Discourse. Cardozo Law Review. v. 17, 1995-1996. p. 1027-1034.

\footnotetext{
—. The Nature of Legal Philosophy. Ratio Juris. v. 17, n. 2, 2004. p. 156-167.

. The Argument from Injustice. A Reply to Legal Positivism. [B. L. Paulson and S. L. Paulson: Begriff und Geltung des Rechts]. Oxford: Clardeon Press, 2002.
}

$\overline{126}$ Cf. DWORKIN, Ronald. A Matter of Principle, p. 205-206. 
The Special Case Thesis. Ratio Juris. v. 12, n. 4, December 1999. p. 374-384.

BRASIL. Constituição da República Federativa do Brasil, promulgada em 05.10.1988.

. Decreto-Lei 3.689, de 3 de outubro de 1941. Código de Processo Penal.

Decreto-Lei 4.657, de 4 de setembro de 1942. Lei de Introdução ao Código Civil Brasileiro.

. Lei 5.869, de 11 de janeiro de 1973. Código de processo civil.

DUTRA, Delamar José Volpato. Da revisão do conceito discursivo de verdade em "Verdade e justificação”. Ethic@. v. 2, n. 2, 2003. p. 219-231. [http://www.cfh.ufsc.br/ethic@].

DWORKIN, Ronald. A Matter of Principle. Cambridge: Harvard University Press, 2000.

. Law's Empire. Cambridge: Harvard University Press, 1986.

Taking Rights Seriously. London: Duckworth, 1977.

ELY, John Hart. The Wages of Crying Wolf: A Comment on Roe v. Wade. Yale Law Journal. v. 82, 1973. p. 920-949.

GÜNTHER, Klaus. Ein normativer Begriff der Kohärenz für eine Theorie der juristischen Argumentation. Rechstheorie. n. 20, 1989. p. 163-190.

HABERMAS, Jürgen. "Between Facts and Norms": an Author's Refletions. Denver University Law Review. v. 76, 1999. p. 937-942.

A Short Reply. Ratio Juris. v. 12, n. 4, December 1999. p. 445-453.

. Direito e democracia: entre faticidade e validade. [v. I]. [Trad. F. B. Siebeneichler: Faktizität und Geltung: Beiträge zur Diskurstheorie des Rechts und des demokratischen Rechtsstaats]. Rio de Janeiro: Tempo Brasileiro, 1997.

. Direito e democracia: entre faticidade e validade. [v. II]. [Trad. F. B. Siebeneichler: Faktizität und Geltung: Beiträge zur Diskurstheorie des Rechts und des demokratischen Rechtsstaats]. Rio de Janeiro: Tempo Brasileiro, 1997.

. Reply to Symposium Participants, Benjamin N. Cardozo School of Law. Cardozo Law Review. v. 17, 1995-1996. p. 1477-1557.

. Paradigms of Law. Cardozo Law Review. v. 17, 1995-1996. p. 771-784.

KRESS, K. J. Legal Reasoning and Coherence Theories: Dworkin's Rights Thesis, Retroactivity, and the Linear Order of Decisions. California Law Review. n. 72, 1984. p. 369-402.

McCORMICK, John P. Habermas's Discourse Theory of Law: Bridging Anglo-American and Continental Legal Traditions? The Modern Law Review. v. 60, 1997. p. 734-743.

MICHELMAN, Frank I. The Supreme Court 1985 Term. Foreword: Traces of Self-Government. Harvard Law Review. v. 100, n. 4, 1986. p. 62-77.

NEUMANN, Ulfrid. Juristische Argumentationslehre. Darmstadt: Wissenschaftliche Buchgesellschaft, 1986.

Zur Interpretation des forensischen Diskurses in der Rechtsphilosophie von Jürgen Habermas. Rechstheorie. n. 27, 1996. p. 415-26

TEUBNER, Gunther. De Collisione Discursuum: Communicative Rationalities in Law, Morality, and Politics. Cardozo Law Review. v. 17, 1995-1996. p. 901-918. 